\title{
Editorial-The 6th International Workshop on Modeling the Ocean (IWMO 2014)
}

\author{
Lie-Yauw Oey ${ }^{1,2} \cdot$ Tal Ezer $^{3}$ (D) Jinyu Sheng ${ }^{4} \cdot$ Fei Chai $^{5} \cdot$ Jianping Gan $^{6} \cdot$ Kevin Lamb $^{7}$. \\ Yasumasa Miyazawa ${ }^{8}$
}

Received: 5 December 2016/Accepted: 7 December 2016/Published online: 28 December 2016

(C) Springer-Verlag Berlin Heidelberg 2016

The 6th International Workshop on Modeling the Ocean (IWMO 2014) was held on June 23-27, 2014, at Dalhousie University in Halifax, Nova Scotia, Canada. After three meetings in Asia (Oey et al. 2010, 2013a, b) and one in Europe (Berntsen et al. 2014), the IWMO returned to North America for the second time (since IWMO 2010 in the USA; Ezer et al. 2011). Readers are referred to https://www.dal.ca/sites/iwmo. html for more information on IWMO 2014 and http://www. ccpo.odu.edu/POMWEB /meetings.htm for information on the past meetings and future planned meetings.

Halifax is the largest city on the east coast of Canada, an international seaport and the center of maritime and marine

Responsible Editor: Jörg-Olaf Wolff

Tal Ezer

tezer@odu.edu

Princeton University, Princeton, NJ, USA

2 National Central University, Taoyuan City, Taiwan

3 Center for Coastal Physical Oceanography, Old Dominion University, 4111 Monarch Way, Norfolk, VA 23508, USA

4 Department of Oceanography, Dalhousie University, 1355 Oxford Street, Halifax, Nova Scotia B3H 4R2, Canada

5 School of Marine Sciences, University of Maine, Orono, ME, USA

6 Department of Mathematics \& Atmospheric Marine and Coastal Environment, Hong Kong University of Science and Technology, Hong Kong, China

7 Applied Mathematics, University of Waterloo, 200 University Avenue West, Waterloo, Ontario N2L 3G1, Canada

8 Japan Agency for Marine-Earth Science and Technology, Yokohama, Japan science. Located between the Atlantic Ocean on the east and the Bay of Fundy on the southwest (where the highest tide in the world is found), Halifax nicely symbolizes the spirit of IWMO of innovative ocean modeling research that addresses both large-scale open ocean circulation and small-scale coastal processes.

More than 80 researchers from 15 countries attended the workshop, which included about 65 oral presentations and 15 posters. The oral and poster presentations covered a wide range of ocean modeling and analysis issues and different geographical locations from the South China Sea and Tokyo Bay to the Pacific, Atlantic, and Indian Oceans. Continuing the tradition of IWMO in encouraging the participation of young scientists, about 20 graduate students and postdocs participated in the competition for the Outstanding Young Scientist Award.

The collection of 13 papers in this Special Issue underwent the same rigorous review process as regular papers of Ocean Dynamics. The reviews were solicited from both the workshop attendees and the scientific community at large. The papers in this issue mainly focus on four major geographic regions:

(1) Five papers addressed modeling of ocean surface gravity waves, sea ice, tides, and storm surges along the northwestern Atlantic Ocean, near Canadian coasts in the vicinity of the location of the meeting (Guo and Sheng 2015; Prasad et al. 2015; Rao et al. 2016; Xu 2015a, b).

(2) Four papers addressed observations and modeling of semi-enclosed seas and bays along the western coasts of the Pacific Ocean, such as the South China Sea and the Tokyo Bay (Guo et al. 2015; Lu et al. 2015; Sun et al. 2015; Wang et al. 2015a). 
(3) Two papers addressed variability in the North (Liu and Wei 2015) and the South (Wang et al. 2015b) Pacific Ocean.

(4) Two papers addressed air-sea and biochemical-physical interactions in the Indian Ocean (Huang et al. 2015; Yan et al. 2015).

In the northwest Atlantic Ocean, Guo and Sheng (2015) simulated 30 years of surface wind waves using the WAVEWATCH model. The extreme significant wave heights in the model were evaluated against wave buoy data. Their results demonstrate significant differences in extreme waves between the Gulf of St. Lawrence and the Gulf of Maine.

Also in the northwestern Atlantic region, including Baffin Bay and the Labrador Sea, Prasad et al. (2015) used a highresolution atmosphere-ocean-ice model to simulate 7 years of sea ice conditions. Experiments evaluated the sensitivity of the model to grid resolution, and remote sensing data were used to validate the model results.

The Bay of Fundy has the highest tides in the world and thus has the potential of providing a source of tidal power. Rao et al. (2016) used the Finite Volume Community Ocean Model (FVCOM) to test different implementations of tidal turbines and determine their power potential. The model can be used to guide and optimize the arrangement of a tidal turbine farm.

A new method of storm surge modeling was proposed by $\mathrm{Xu}(2015 \mathrm{a})$ and then tested for prediction in the Gulf of St. Lawrence (Xu 2015b). The pre-calculated all-source Green's function (ASGF) method is much faster than traditional methods based on linear dynamics. The ASGF method can lead to the development of an efficient global data assimilation system. Validation of this method was done by comparison with the analytical solution of a storm surge event.

Three papers dealt with different aspects and impacts in the South China Sea (SCS). The first paper by Guo et al. (2015) used a coupled physical-biogeochemical model based on the Regional Ocean Model System (ROMS) and the Carbon, Silicate, and Nitrogen Ecosystem (CoSiNE) model. Analysis of 568 mesoscale eddies revealed differences between cyclonic eddies that were associated with abundance of nutrients and anti-cyclonic eddies that depressed biogeochemical activities.

The second paper on the SCS (Wang et al. 2015a) used the FVCOM to study upwelling systems during the summer monsoon season. The model results revealed the impacts of tidal mixing, surface wind-wave mixing, and river runoff. It was found that river runoff and wave mixing suppress upwelling and keeps it below the thermocline while tidal mixing was the main cause of inducing upwelling.

The third paper on the SCS and the nearby western North Pacific (Sun et al. 2015) used the Princeton Ocean Model (POM) to study the ocean response to Typhoon Nuri in August 2008. Satellite SST and altimetry data from the period before the storm were used to construct the pre-storm ocean state. The non-assimilative simulations during the storm showed strong cooling on the right side of the storm's track with much more intense cooling in the SCS than in the Pacific. The different cooling was explained by the different resonance response between wind and currents in the two basins.

Another study of a semi-enclosed bay in the western North Pacific (Lu et al. 2015) was numerical simulations of Tokyo Bay, Japan, using the finite volume model Multi-Scale Simulator for the Geoenvironment (MSSG). Sensitivity experiments with different wind fields show the significant effect that winds have on heat transport and temperature pattern in the bay. In particular, wind direction significantly impacts water temperatures in the bay, so past trends of increasing southerly wind from 1979 to 1997 may have affected water temperature trends.

Two papers used observations and models to study processes and variability in the North and South Pacific. First, Liu and Wei (2015) used the observed SST and Argo data as well as idealized numerical simulations to study the impact of tropical cyclones on temperatures near the Kuroshio. This study found that subsurface water temperatures near the Kuroshio showed rapid warming and recovery after the passage of cyclones. Downwelling and transport by the Kuroshio played important roles in the short recovery time.

The second paper on the Pacific Ocean (Wang et al. 2015b) used reanalysis data and heat flux data to study the seasonal and inter-annual variability of the western subtropical mode water in the South Pacific Ocean. Surface heat flux and the East Australian Current (EAC) heat transport were found to compensate one another in the heat budget. The study revealed the important role played by the EAC in the interannual variability in the South Pacific Ocean.

Two papers focused on observations and models in the Indian Ocean. First, Huang et al. (2015) used a coupled physical-biochemical model based on the Navy Coastal Ocean Model (NCOM) and the CoSiNE model to provide estimates of the physical and biochemical state of the ocean. Basin-scale circulation patterns and crosssectional transports were compared favorably with observations. The seasonality associated with the monsoonal forcing was examined, suggesting the need for further studies to understand the instability of the coupled ocean-atmosphere system in the region.

The second paper on the Indian Ocean (Yan et al. 2015) analyzed changes in oceanographic and atmospheric conditions after the 2004 Indian Ocean tsunami, using satellite remote sensing and reanalysis atmospheric data. After the tsunami, rainfall over deep waters near Sri Lanka increased and SST there cooled, while temperatures warmed after the tsuna$\mathrm{mi}$ in regions southwest of the epicenter. Biological variables also changed after the change in SST. 
Acknowledgements The host of the meeting, Jinyu Sheng, and his dedicated local organizing group are thanked for their warm hospitality and help during the workshop as well as for providing a wonderful evening of entertainment by local talents. Sponsors include The Marine Environmental Observation Prediction and Response Network (MEOPAR), Lloyd's Register Foundation, Department of Oceanography, and President's Office of Dalhousie University. All the reviewers are thanked for their time and efforts.

\section{References}

Berntsen J, Oey L-Y, Ezer T, Greatbatch R, Xue H, Miyazawa M (2014) Editorial-The 5th International Workshop on Modeling the Ocean (IWMO-2013). Ocean Dyn 64(10):15311534. doi: $10.1007 / \mathrm{s} 10236-014-0764-\mathrm{Z}$

Ezer T, Oey L-Y, Xue H, Wang XH (2011) Editorial-the 2nd International Workshop on Modeling the Ocean (IWMO-2010). Ocean Dyn 61:1287-1289. doi:10.1007/s10236-011-0470-z

Guo M, Chai F, Xiu P (2015) Impacts of mesoscale eddies in the South China Sea on biogeochemical cycles. Ocean Dyn 65(9):1335-1352. doi:10.1007/s10236-015-0867-1

Guo L, Sheng J (2015) Statistical estimation of extreme ocean waves over the eastern Canadian shelf from 30-year numerical wave simulation. Ocean Dyn 65(11):1489-1507. doi:10.1007/s10236-015-0878-y

Huang K, Derada S, Xue H, Xiu P, Chai F, Xie Q, Wang D (2015) A 1/8 coupled biochemical-physical Indian Ocean regional model: physical results and validation. Ocean Dyn 65(8):1121-1142. doi:10.1007/s10236-015-0860-8

Liu X, Wei J (2015) Understanding surface and subsurface temperature changes induced by tropical cyclones in the Kuroshio. Ocean Dyn 65(7):1017-1027. doi:10.1007/s10236-015-0851-9

Lu LF, Onishi R, Takahashi K (2015) The effect of wind on long-term summer water temperature trends in Tokyo Bay, Japan. Ocean Dyn 65(6):919-930. doi:10.1007/s10236-015-0848-4

Oey L-Y, Ezer T, Miyazawa Y, Wu C-R (2010) EditorialInternational Workshop on Modeling the Ocean (IWMO) special issue in ocean dynamics. Ocean Dyn 60:299-300. doi:10.1007/s10236-010-0281-7

Oey L-Y, Ezer T, Qiu B, Berntsen J, He R (2013a) Editorial-The 3rd International Workshop on Modeling the Ocean (IWMO 2011). Ocean Dyn 63:307-309. doi:10.1007/s10236-013-0595-3

Oey L-Y, Miyazawa Y, Aiki H, Masumoto Y, Ezer T, Waseda T (2013b) Editorial - the 4th International Workshop on Modeling the Ocean (IWMO 2012). Ocean Dyn 63:13451347. doi:10.1007/s10236-013-0658-5

Prasad S, Zakharov I, Bobby P, McGuire P (2015) The implementation of sea ice model on a regional high-resolution scale. Ocean Dyn 65(9): 1353-1366. doi:10.1007/s10236-015-0877-z

Rao S, Xue H, Bao M, Funke S (2016) Determining tidal turbine farm efficiency in the Western Passage using the disc actuator theory. Ocean Dyn 66:41-57. doi:10.1007/s10236-015-0906-y

Sun J, Oey L-Y, Chang R, Xu F, Huang S-M (2015) Ocean response to typhoon Nuri (2008) in western Pacific and South China Sea. Ocean Dyn 65(5):735-749. doi:10.1007/s10236-015-0823-0

Wang D, Yang Y, Wang J, Bai X (2015a) A modeling study of the effects of river runoff, tides, and surface wind-wave mixing on the Eastern and Western Hainan upwelling systems of the South China Sea, China. Ocean Dyn 65(8):1143-1164. doi:10.1007/s10236-015-0857-3

Wang XH, Bhatt V, Sun YJ (2015b) Seasonal and inter-annual variability of western subtropical mode water in the South Pacific Ocean. Ocean Dyn 65:143-154. doi:10.1007/s10236-014-0792-8

$\mathrm{Xu}$ Z (2015a) The all-source Green's function (ASGF) and its applications to storm surge modeling, part I: from the governing equations to the ASGF convolution. Ocean Dyn 65(12):1743-1760. doi:10.1007/s10236-015-0893-Z

$\mathrm{Xu} \mathrm{Z} \mathrm{(2015b)} \mathrm{The} \mathrm{all-source} \mathrm{Green's} \mathrm{function} \mathrm{(ASGF)} \mathrm{and} \mathrm{its} \mathrm{applica-}$ tions to storm surge modeling, part II: from the ASGF convolution to forcing data compression and a regression model. Ocean Dyn 65(12):1761-1778. doi:10.1007/ s10236-015-0894-y

Yan Z, Sui Y, Sheng J, Tang D, Lin I-I (2015) Changes in local oceanographic and atmospheric conditions shortly after the 2004 Indian Ocean tsunami. Ocean Dyn 65(6):905-918. doi:10.1007/s10236-015-0838-6 